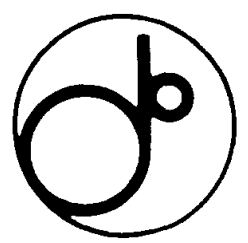

KEK Preprint 93-142

HUPD-9326

KOBE HEP-9310

KUNS-1225

OUHEP 93-5

OULNS 93-05

TMU-HEP 93-5

November 1993

$\mathbf{H}$

\title{
Measurement of Open Charm Production in Two-Photon Processes with Detection of Electron-Inclusive Events
}

VENUS Collaboration

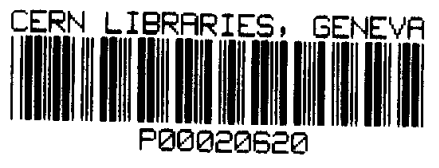

Submitted for publication 
National Laboratory for High Energy Physics, 1993

KEK Reports are available from:

Technical Information \& Library

National Laboratory for High Energy Physics

1-1 Oho, Tsukuba-shi

Ibaraki-ken, 305

JAPAN

Phone: $\quad 0298-64-1171$

Telex: $\quad 3652-534$ (Domestic)

(0)3652-534 (International)

Fax: $\quad 0298-64-4604$

Cable: KEK OHO

E-mail: LIBRARY@JPNKEKVX (Bitnet Address)

library@kekvax.kek.jp (Internet Address) 

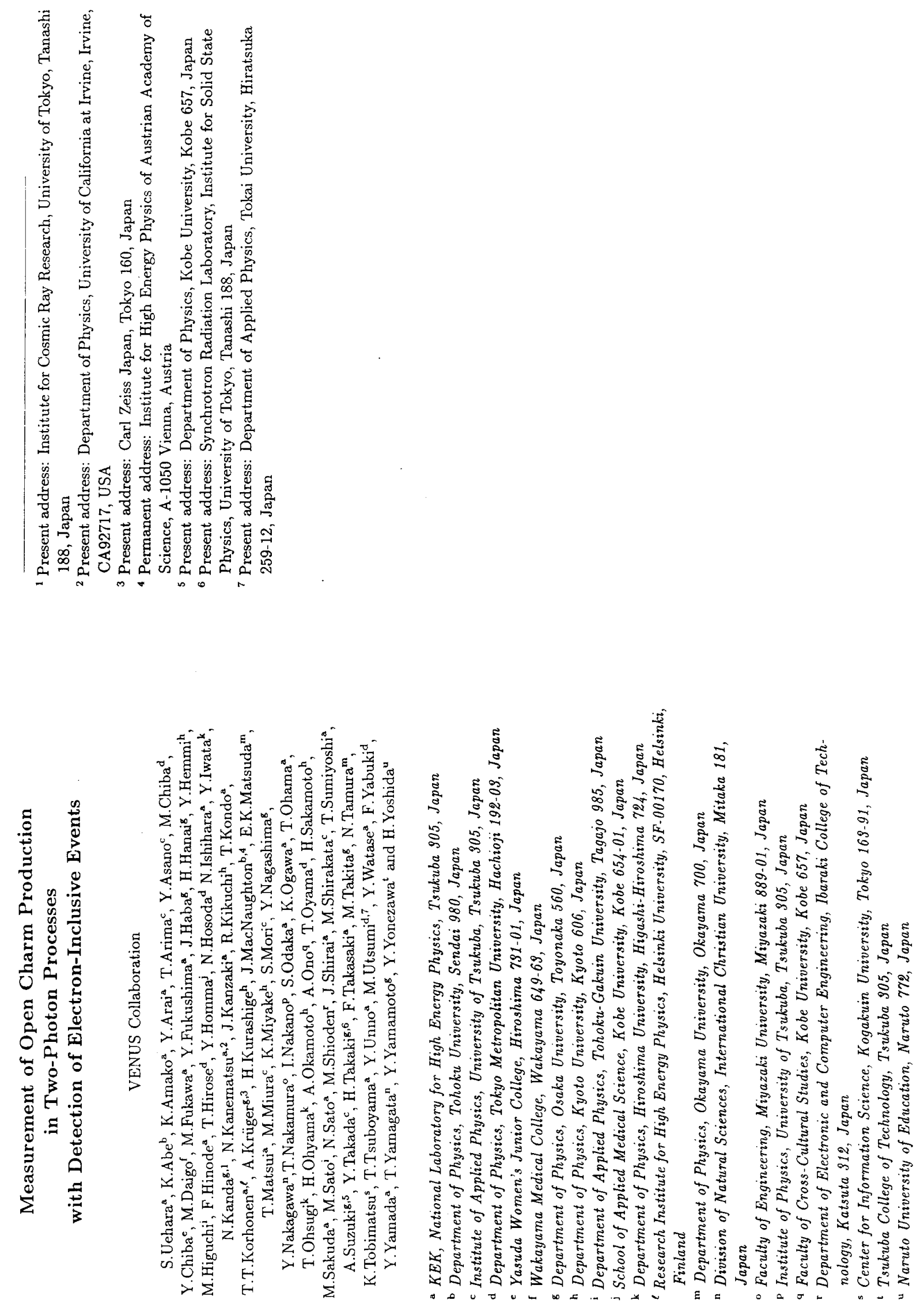

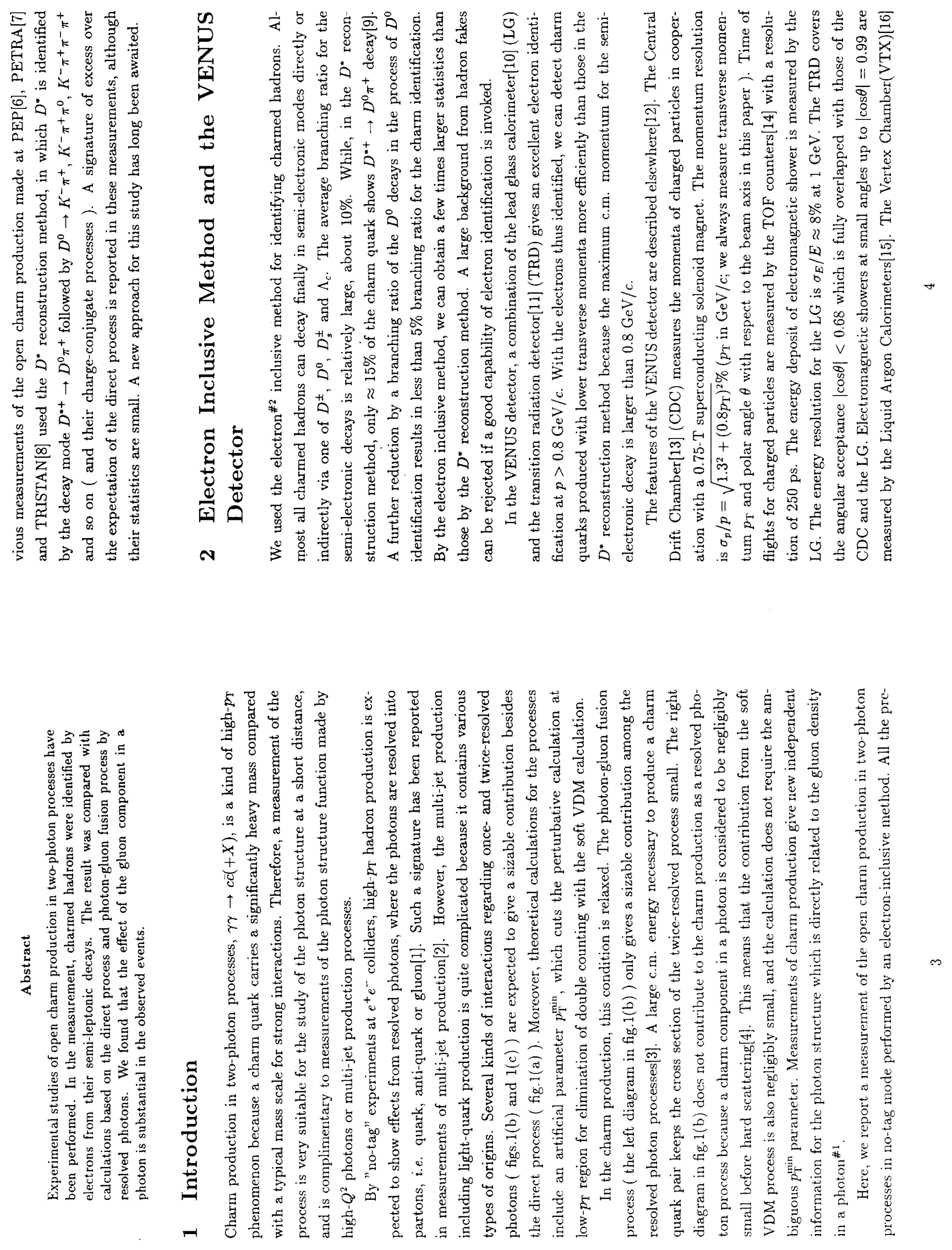


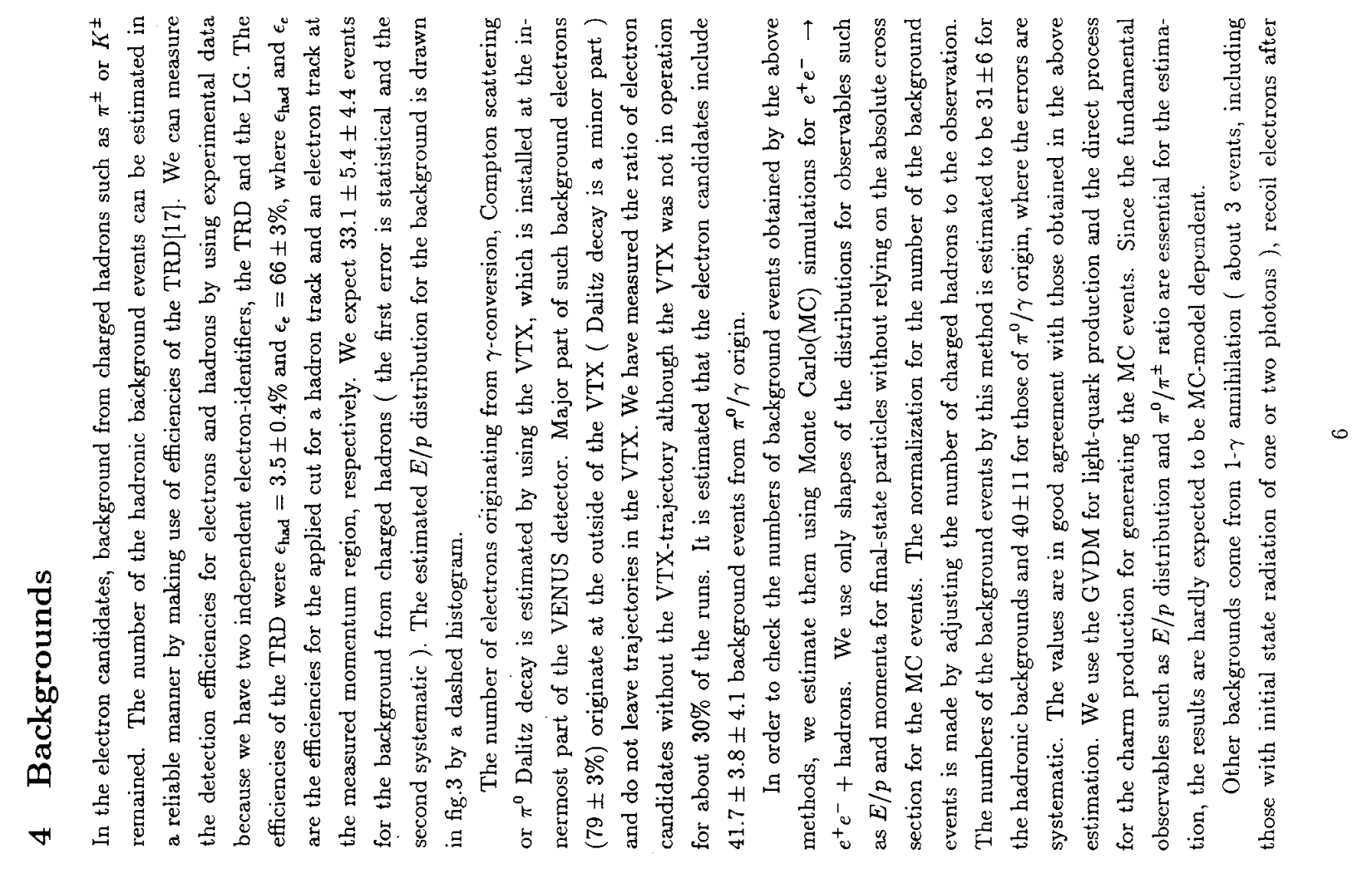

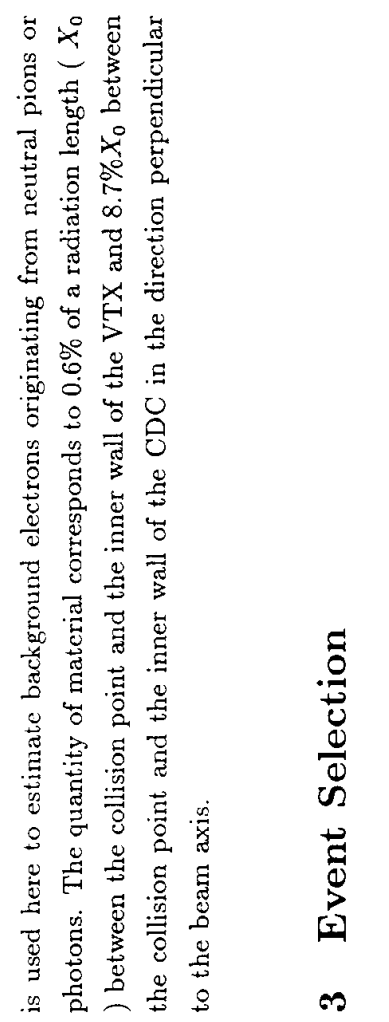

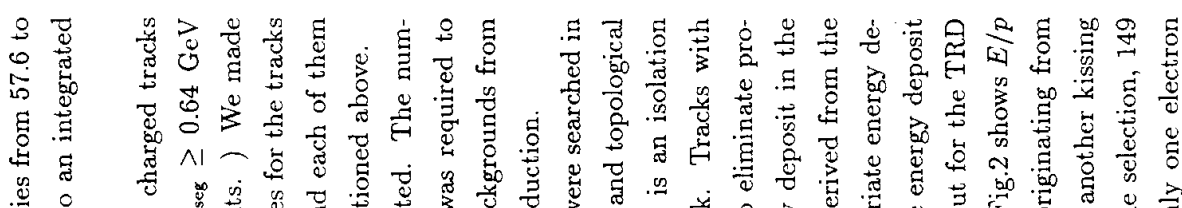

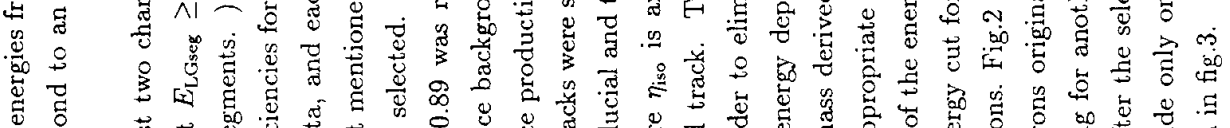

I MU

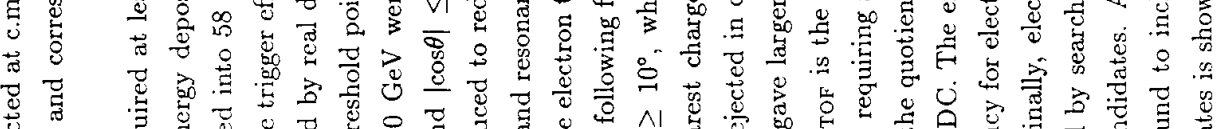

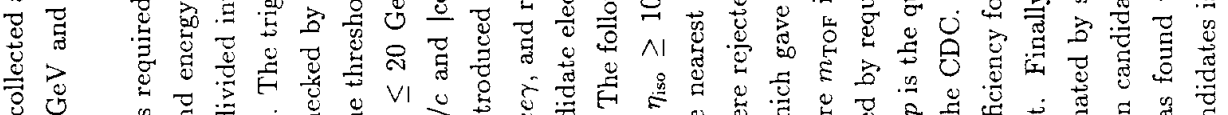

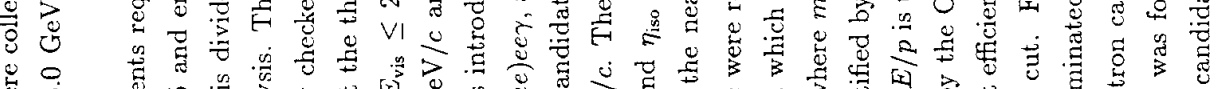

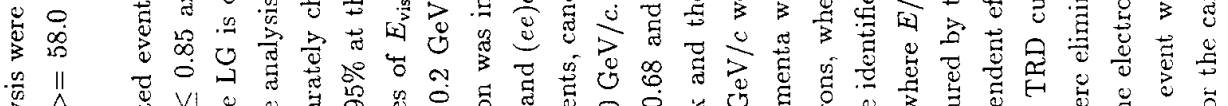

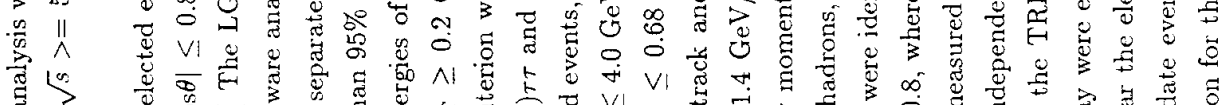

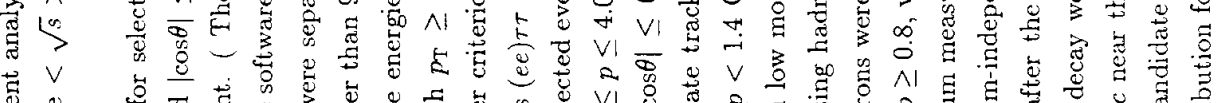

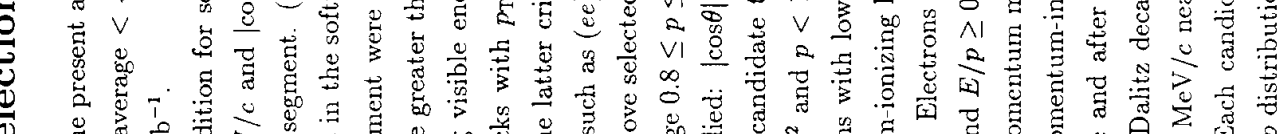

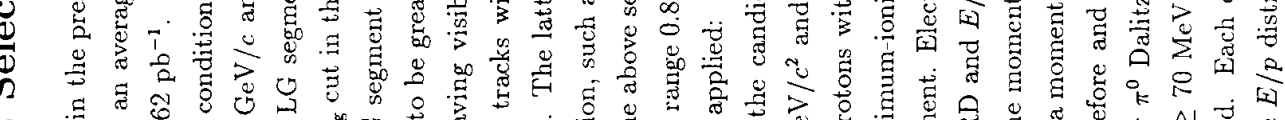

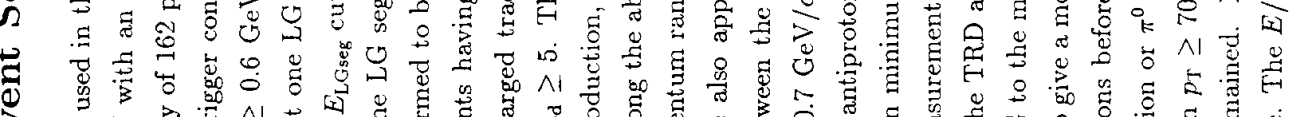

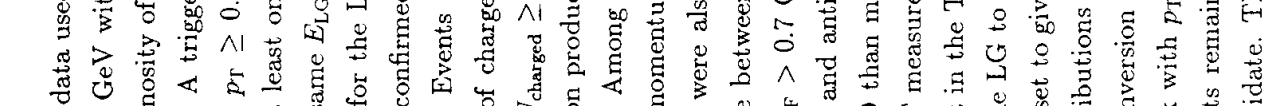

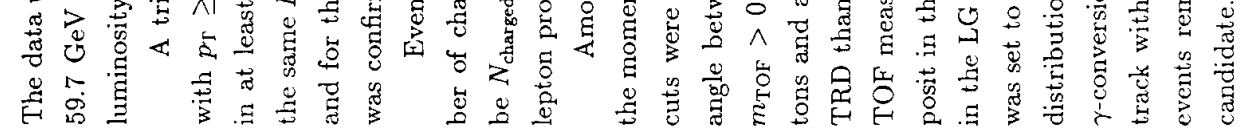



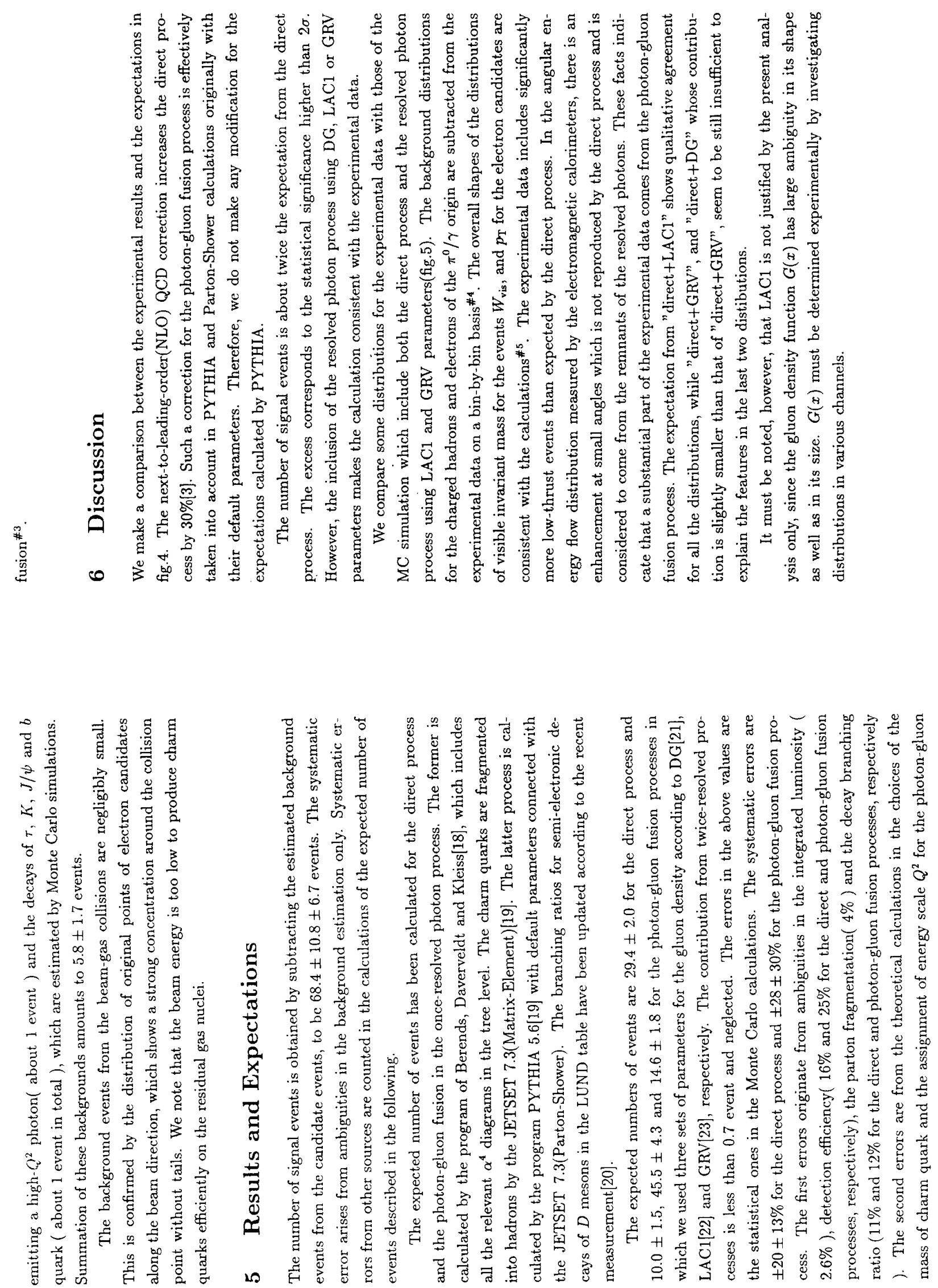


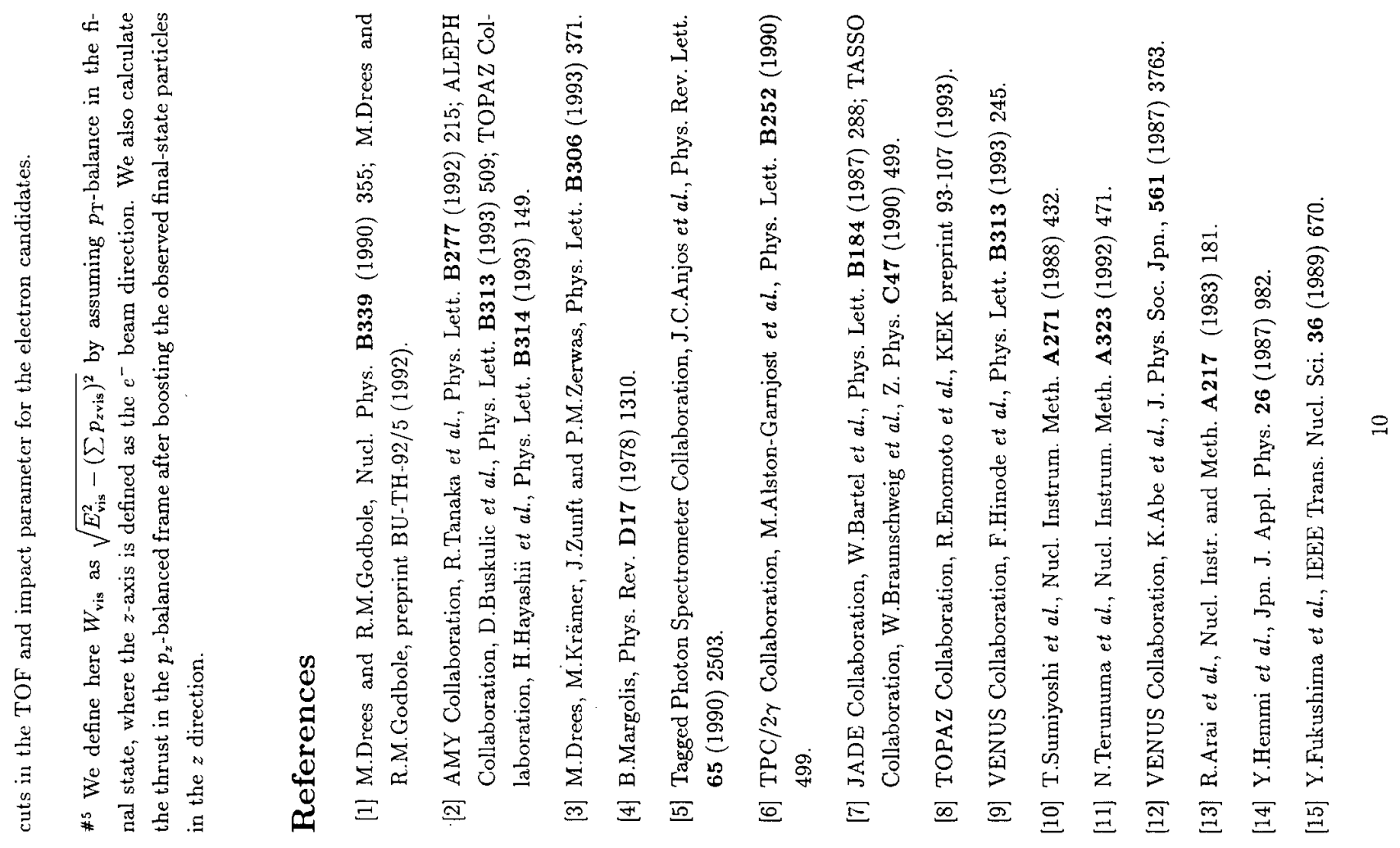

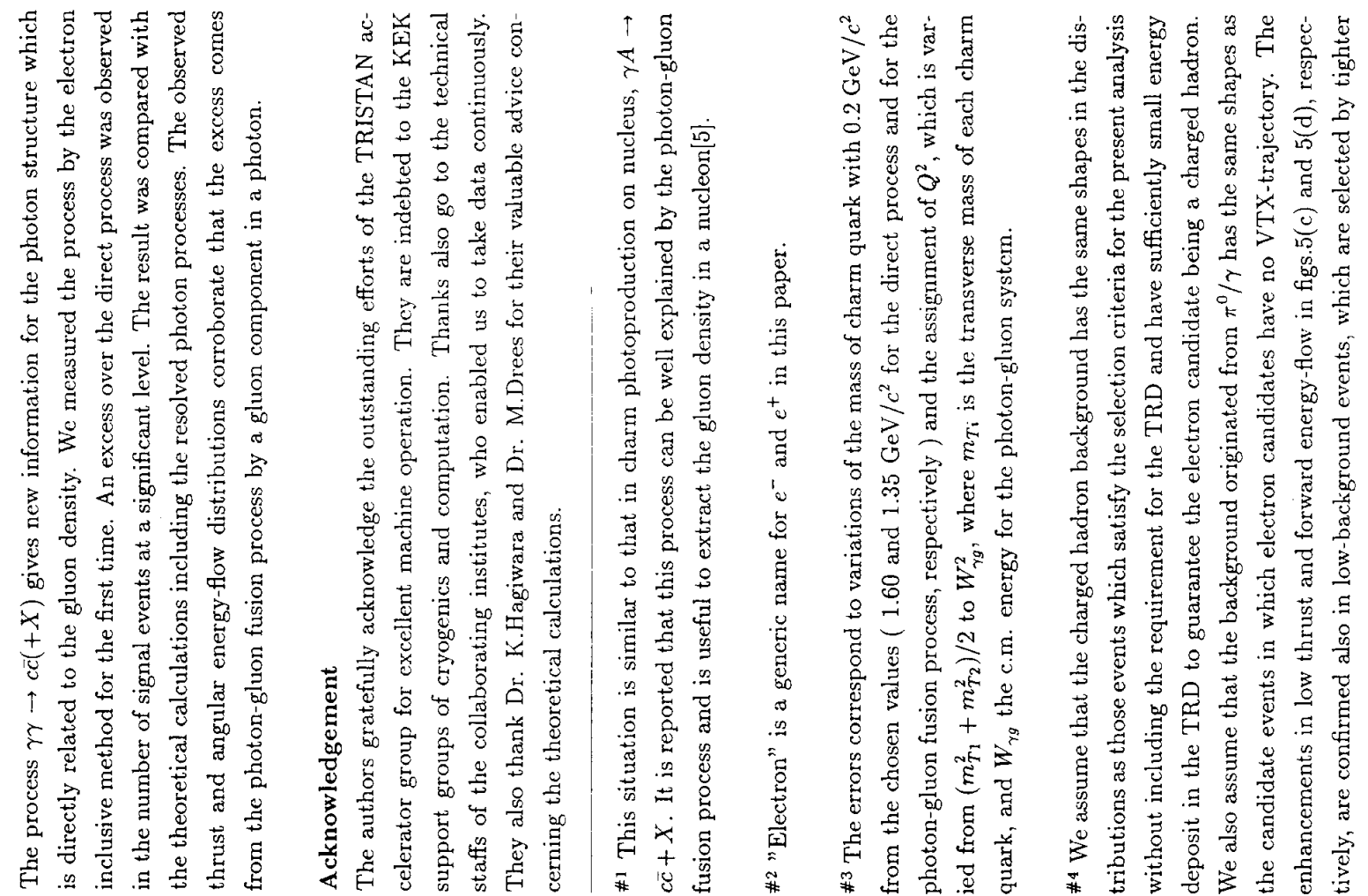




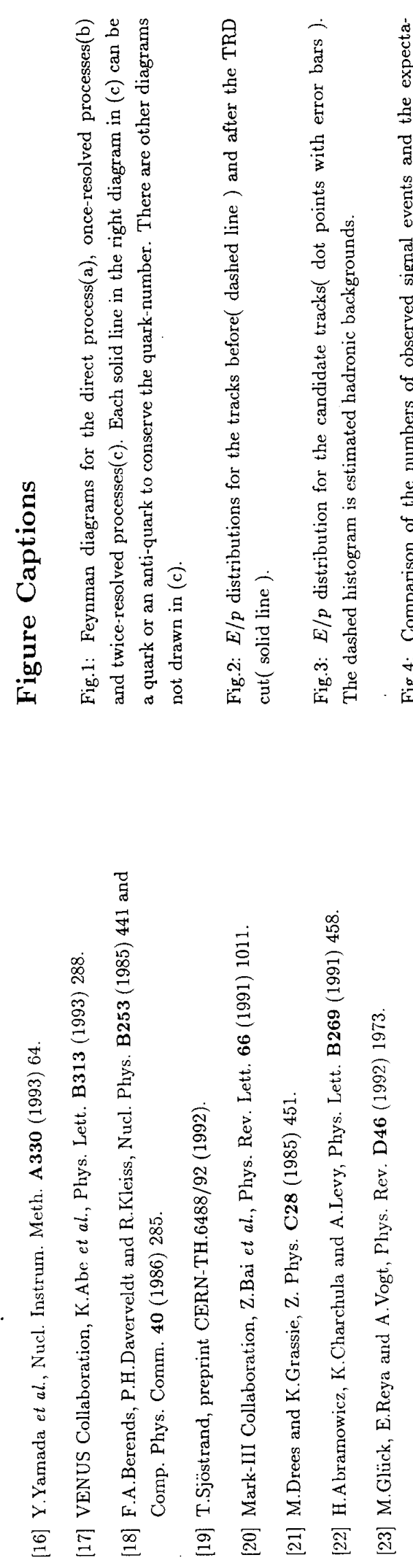




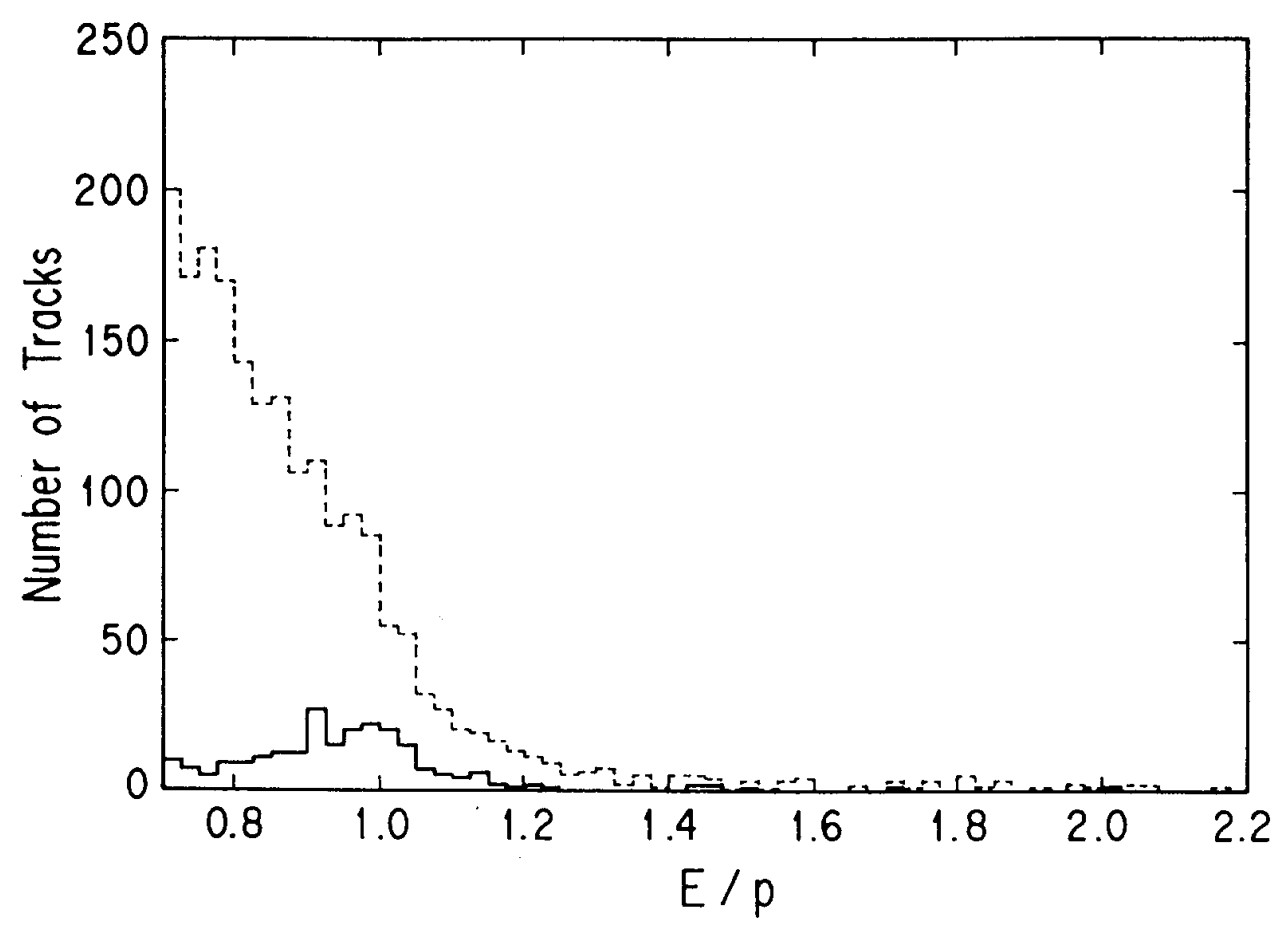

Fig.2

(a)

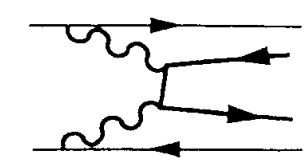

(b)
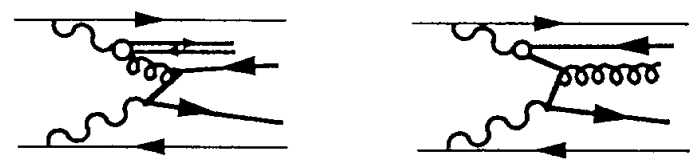

(c)
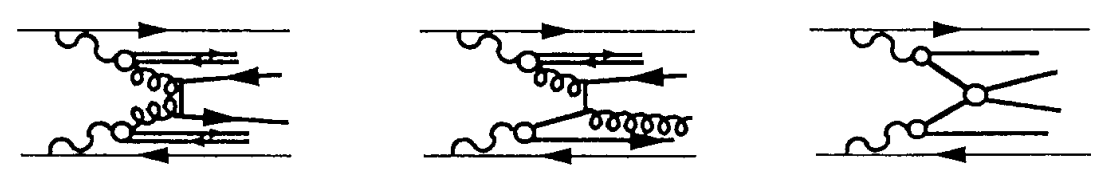

Fig.1 


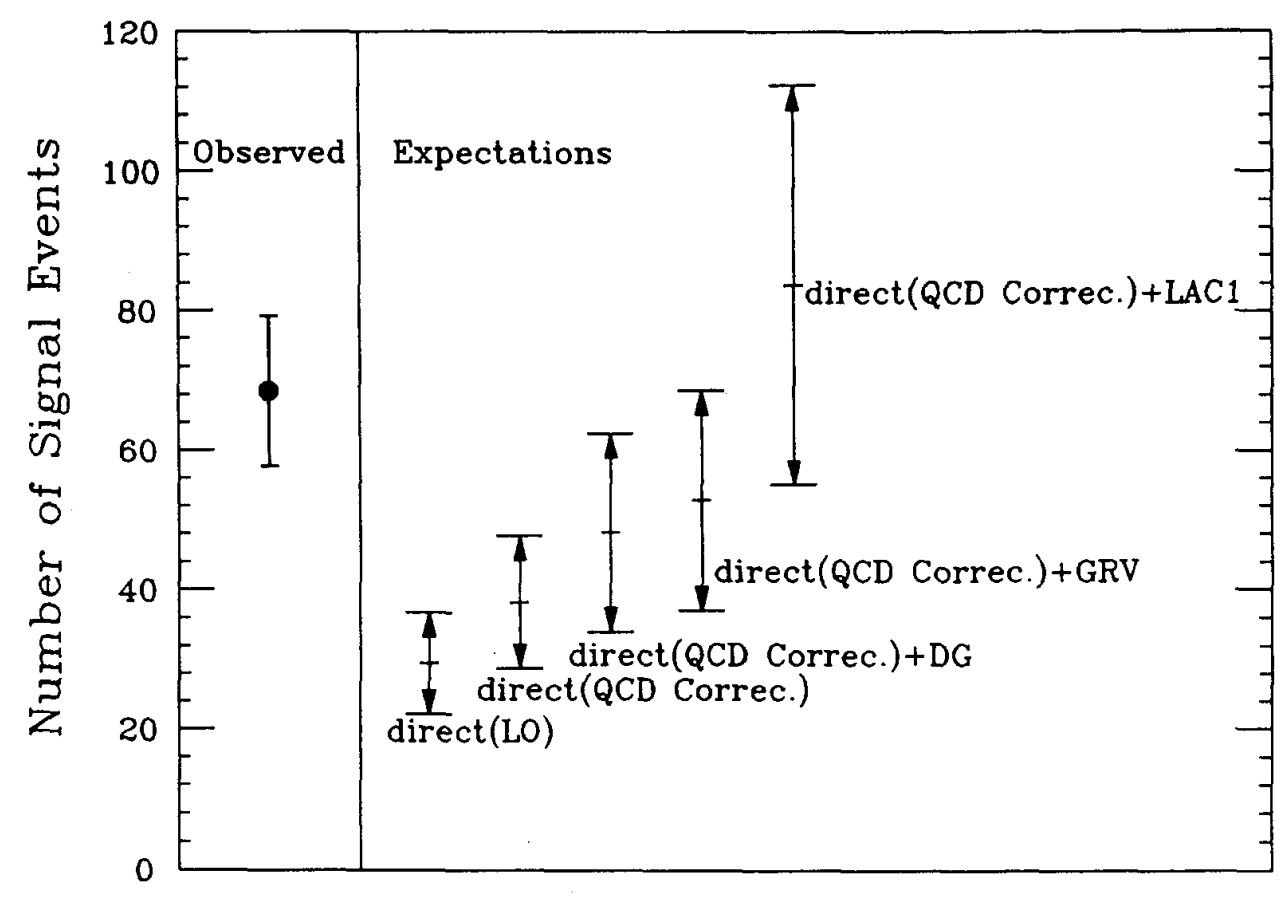

Fig.4

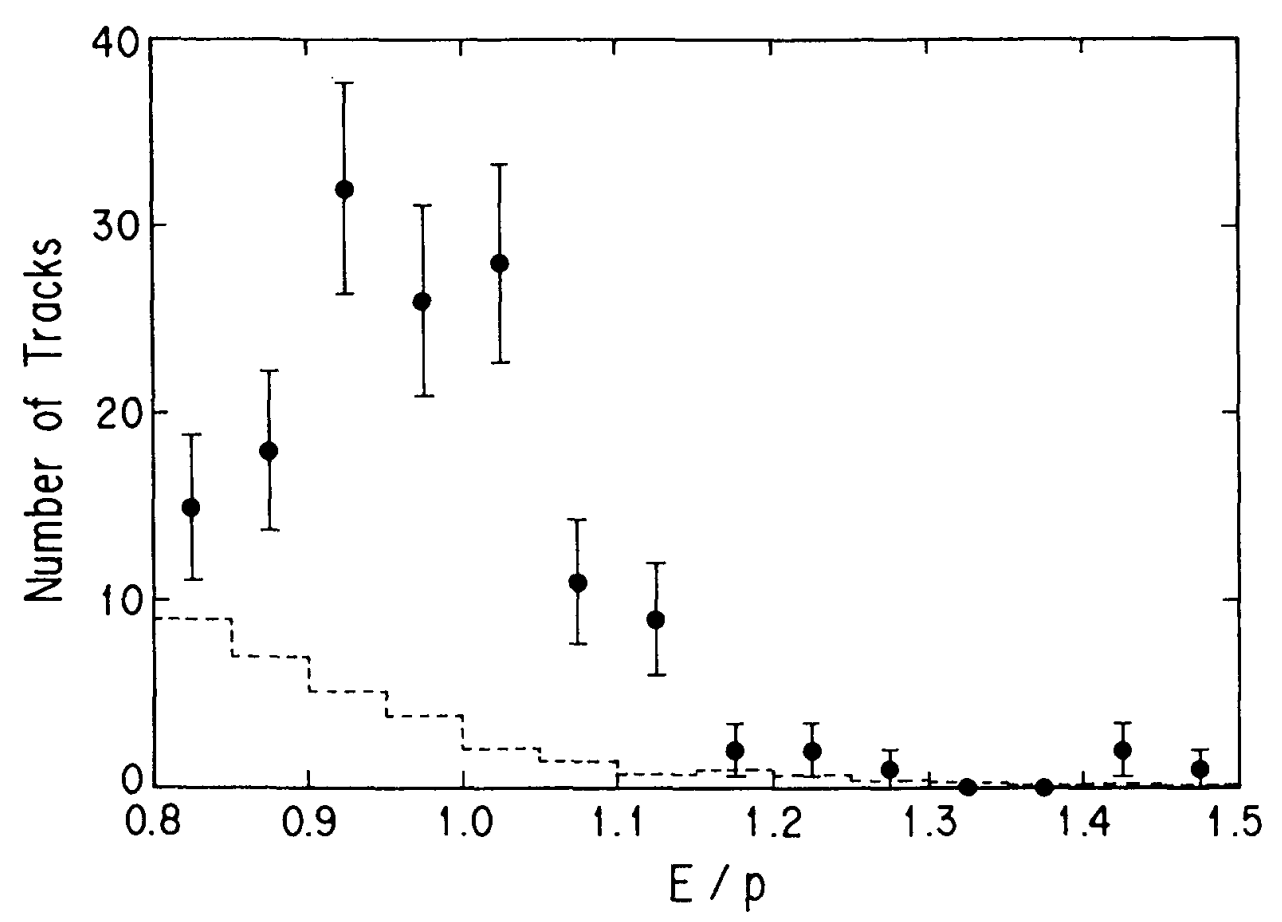

Fig. 3 

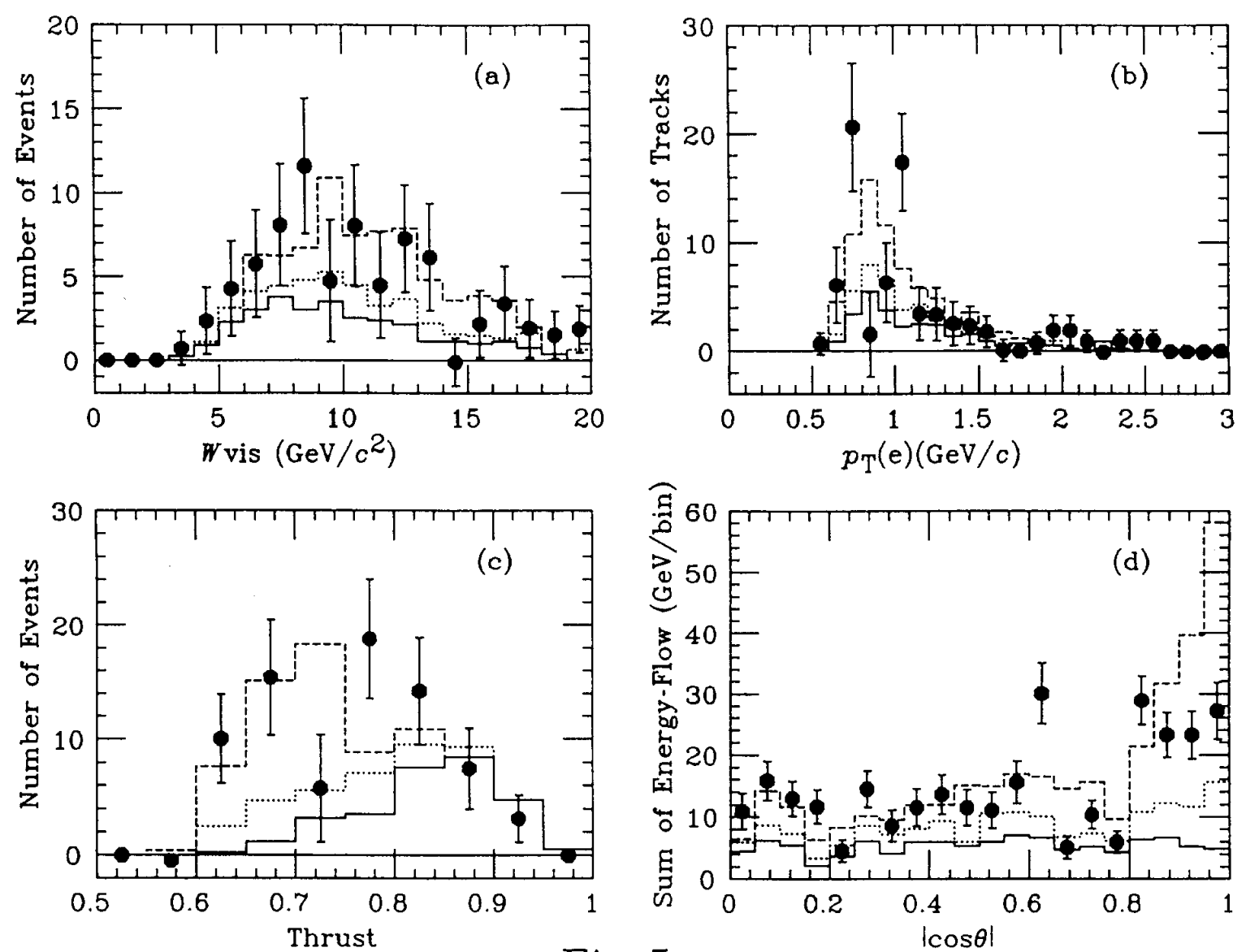

Fig. 5 
